\title{
Strategi Kemitraan Pelaksanaan Layanan Bimbingan Dan Konseling Melalui Kegiatan Parenting Bagi Wali Murid Di Lembaga PAUD Kecamatan Kedungbanteng Kabupaten Banyumas
}

\author{
Novan Ardy Wiyani \\ IAIN Purwokerto, \\ e-mail: fenomenajiwa@gmail.com
}

\begin{abstract}
ABSTRAK
Kegiatan pengabdian kepada masyarakat ini ditujukan untuk memberikan bekal pengetahuan dan pengalaman bagi orangtua dalam mengatasi masalah tumbuh-kembang anak usia dini. Ada empat kegiatan yang dilaksanakan untuk mencapai tujuan tersebut. Pertama, sosialisasi program kegiatan pengabdian masyarakat kepada HIMPAUDI kecamatan Kedungbanteng kabupaten Banyumas propinsi Jawa Tengah. Kedua, penandatanganan Memorandum of Understanding (MoU) antara Fakultas Tarbiyah dan Ilmu Keguruan (FTIK) IAIN Purwokerto dengan HIMPAUDI kecamatan Kedungbanteng tentang pelaksanaan layanan bimbingan dan konseling melalui kegiatan parenting bagi wali murid. Ketiga, pelaksanaan layanan bimbingan dan konseling melalui kegiatan parenting bagi wali murid. Keempat, pelaporan kegiatan pelaksanaan layanan bimbingan dan konseling melalui kegiatan parenting bagi wali murid.
\end{abstract}

Kata Kunci: Layanan, Bimbingan dan Konseling, Parenting, Wali Murid

\begin{abstract}
Community service activities are intended to provide knowledge and experience for parents in overcoming problems of early childhood development. There are four activities carried out to achieve this goal. First, the socialization program of community service activities to HIMPAUDI Kedungbanteng district, Banyumas district, Central Java province. Second, the signing of a Memorandum of Understanding (MoU) between the Tarbiyah Faculty and Teacher Training (FTIK) IAIN Purwokerto with the HIMPAUDI of Kedungbanteng sub-district regarding the implementation of guidance and counseling services through parenting activities for student guardians. Third, the implementation of guidance and counseling services through parenting activities for student guardians. Fourth, reporting the activities of guidance and counseling services through parenting activities for student guardians.
\end{abstract}

Keywords: Service, Guidance and Counseling, Parenting, Student Guardians 


\section{PENDAHULUAN}

Keluarga merupakan unit sosial terkecil di masyarakat yang terbentuk atas dasar komitmen untuk mewujudkan fungsi keluarga, fungsi sosial, dan fungsi pendidikan (Yani, Khaeriyah, \& Ulfah, 2017). Aktor utama dalam keluarga adalah orangtua. Pada fungsi pendidikan, orangtua merupakan pendidik yang pertama dan utama bagi anak. Posisi orangtua tersebut menjadikan para orangtua intens dalam mendidik anak. Namun sayangnya tidak semua orangtua mampu melakukannya. Penyebabnya adalah karena faktor keilmuan dalam mendidik anak dan karena faktor keterbatasan waktu serta sarana dan prasarana dalam mendidik anak.

Keterbatasan pada orangtua di atas menjadikannya kemudian menyerahkan urusan pendidikan anaknya kepada guru-guru di lembaga pendidikan, termasuk kepada guru-guru PAUD di lembaga PAUD. Namun ini bukan berarti tanggungjawab mendidik anak telah berpindah dari orangtua kepada guru PAUD. Guru PAUD menjadi mitra bagi orangtua dalam mendidik anak. Kemitraan tersebut terjalin dengan melakukan kerjasama antara orangtua dengan guru PAUD dalam mendidik anak.

Itulah sebab dalam konteks penyelenggaraan layanan PAUD aspek kerjasama antara orangtua dengan guru PAUD mutlak harus diperhatikan oleh guru PAUD. Namun sayangnya masih mudah ditemukan guru PAUD yang enggan berkomunikasi secara intensif dengan orangtua, sehingga menimbulkan miskomunikasi antara guru PAUD dengan orangtua dalam mendidik anak. Pentingnya komunikasi intensif guru dengan orangtua juga penting dalam mengkomunikasikan perkembangan anak serta hal-hal baik yang telah diajarkan di lembaga PAUD (Saripudin, 2019).

Tumbuh-kembang anak usia dini menjadi hal yang sebaiknya intens dikomunikasikan oleh orangtua dan guru PAUD karena memang pada dasarnya PAUD ditujukan untuk memberikan pengasuhan dan pembimbingan yang memungkinkan anak usia dini tumbuh dan berkembang sesuai dengan usia serta potensinya (Wiyani, 2016). Informasi terkait dengan pencapaian tumbuhkembang anak pada komunikasi yang terjalin antara orangtua dan guru PAUD membuat orangtua mengetahui apakah yang diekspektasikannya sudah terwujud atau belum (Wiyani, 2014).

Tentunya ada salah satu aspek atau bahkan lebih tumbuh-kembang anak yang belum sesuai dengan ekspektasi orangtua. Ini berarti kerjasama antara guru PAUD dengan orangtua dalam mendidik anak harus dilakukan lebih optimal lagi. Untuk memunculkan kerjasama tersebut pihak lembaga PAUD perlu menyelenggarakan praktek layanan bimbingan dan konseling bagi wali murid. Praktek layanan bimbingan dan konseling bagi wali murid ini disebut dengan layanan konsultasi. Khamim Zarkasih Putro dan Suyadi mengungkapkan bahwa layanan konsultasi merupakan layanan bimbingan dan konseling yang diberikan oleh guru PAUD kepada wali murid 
agar mendapatkan wawasan, pemahaman dan cara-cara serta perlakuan yang perlu dilakukan untuk mengoptimalkan tumbuh-kembang anak (Putro \& Suyadi, 2016).

Pada pelaksanaan layanan bimbingan dan konseling dengan jenis layanan konsultasi diperlukan berbagai media dan aktivitas sebagai bantuan untuk mencapai tujuan dari kegiatan layanan bimbingan dan konseling (Izzaty, 2017). Salah satu media dan aktivitas yang dapat digunakan untuk menyelenggarakan layanan bimbingan dan konseling dengan jenis layanan konsultasi adalah kegiatan parenting.

Parenting merupakan kegiatan pembimbingan yang diberikan kepada orangtua agar memiliki kemampuan dalam mendiagnosa masalah tumbuh-kembang anak serta agar memiliki kemampuan dalam mengatasi masalah-masalah tersebut (Latif, 2014). Guru PAUD dapat menjadi pihak yang memberikan materi (narasumber) pada kegiatan parenting. Namun sungguh disayangkan, belum semua guru PAUD mampu menjadi narasumber pada kegiatan parenting. Ada dua hal yang menjadi penyebab. Pertama, karena keterbatasan keilmuan guru PAUD terkait dengan pendidikan anak. Kedua, karena keterbatasan terhadap penguasaan metodologi pendidikan dalam perspektif andragogi. Hal inilah yang sedang dialami oleh guru-guru PAUD di lembaga PAUD non formal yang berada di kecamatan Kedungbanteng kabupaten Banyumas propinsi Jawa Tengah.

Berdasarkan masalah dan penyebab masalah di atas kemudian penulis terdorong untuk melakukan kerjasama atau kemitraan dengan HIMPAUDI kecamatan Kedungbanteng kabupaten Banyumas untuk melaksanakan layanan bimbingan dan konseling melalui kegiatan parenting bagi wali murid pada lembaga PAUD di kecamatan Kedungbanteng kabupaten Banyumas. Tujuan dari dilakukannya kegiatan ini adalah untuk memberikan bekal pengetahuan dan pengalaman bagi orangtua dalam mengatasi masalah tumbuh-kembang anak usia dini.

\section{BAHAN DAN METODE}

Kegiatan pengabdian kepada masyarakat ini menggunakan metode Partisipatory Action Research (PAR). Metode PAR dipilih karena bentuk kegiatan pengabdian masyarakat ditentukan berdasarkan permasalahan yang dihadapi oleh lembaga PAUD di kecamatan Kedungbanteng kabupaten Banyumas.

Kegiatan pengabdian kepada masyarakat berupa pelaksanaan layanan bimbingan dan konseling bagi wali murid di lembaga PAUD pada kecamatan Kedungbanteng kabupaten Banyumas dilaksanakan melalui strategi kemitraan. Berdasarkan strategi tersebut maka ada empat langkah yang dilakukan dalam kegiatan pengabdian kepada masyarakat ini. Pertama, sosialisasi program kegiatan pengabdian masyarakat kepada HIMPAUDI kecamatan Kedungbanteng 
kabupaten Banyumas propinsi Jawa Tengah. Kedua, penandatanganan Memorandum of Understanding (MoU) antara Fakultas Tarbiyah dan Ilmu Keguruan (FTIK) IAIN Purwokerto dengan HIMPAUDI kecamatan Kedungbanteng tentang pelaksanaan layanan bimbingan dan konseling melalui kegiatan parenting bagi wali murid. Ketiga, pelaksanaan layanan bimbingan dan konseling melalui kegiatan parenting bagi wali murid. Keempat, pelaporan kegiatan pelaksanaan layanan bimbingan dan konseling melalui kegiatan parenting bagi wali murid.

\section{HASIL DAN PEMBAHASAN}

Pelaksanaan layanan bimbingan dan konseling melalui kegiatan parenting bagi wali murid pada lembaga PAUD di kecamatan Kedungbanteng kabupaten Banyumas diikuti oleh 20 lembaga PAUD non formal dengan rincian sebagai berikut:

Tabel 1. Lembaga PAUD Non Formal Peserta Kegiatan Parenting

\begin{tabular}{|l|l|l|}
\hline No. & \multicolumn{1}{|c|}{ Nama Lembaga PAUD } & Nama Kepala Lembaga PAUD \\
\hline 1 & KB Aisyiyah Beji & Lina Kristianik \\
\hline 2 & PosPAUD Mawar II Baseh & Ambar Siti Suswanti \\
\hline 3 & $\begin{array}{l}\text { PosPAUD Windu Cahaya } \\
\text { Windujaya }\end{array}$ & Nuning Retno H \\
\hline 4 & $\begin{array}{l}\text { PosPAUD Cempaka III Dawuhan } \\
\text { Wetan }\end{array}$ & Lilis Suryatini, S.Pd \\
\hline 5 & PAUD TPQ An-Nasriyah Beji & Rani Istikharoh, S.Pd \\
\hline 6 & KB Tunas Perjuangan Kalisalak & Masrokha, S.Ag \\
\hline 7 & KB Tunas Bangsa Kedungbanteng & Umi Habibah, S.Pd \\
\hline 8 & KB Bunga Pertiwi Baseh & Tri Uswatun Khasanah \\
\hline 9 & KB Berseri Kebocoran & Kuswati \\
\hline 10 & KB Tunas Harapan Windujaya & Evi Kurniasari Dewi, A.Md \\
\hline 11 & KB Satria Jaya Melung & Tri Yani \\
\hline 12 & KB Putra Mandiri Keniten & Tarsiki \\
\hline 13 & KB Banyu Belik Karangnangka & Septi Larasakti, S.Kom \\
\hline 14 & KB al-Manar Beji & Sumirah \\
\hline 15 & PosPAUD Mawar VII Dawuhan & Susmiyati \\
\hline 16 & KB Asy-Syahadah Karangnangka & Fina Bahagiowati \\
\hline 17 & KB Islam al-Izzah Karangsalam & Septi Riawati \\
\hline
\end{tabular}




\begin{tabular}{|l|l|l|}
\hline 18 & KB Patriadira Kalikesur & Kusrianingsih \\
\hline 19 & KB Nur Amanah Kutaliman & Tohinah \\
\hline 20 & KB Az-Zahra Dawuhan Kulon & Sri Kasirotun, S.Pd \\
\hline
\end{tabular}

Kegiatan parenting berlangsung pada hari Selasa dan Rabu 17 hingga 18 September 2019 bertempat di aula UPK Kedungbanteng Banyumas. Pada Selasa 17 September 2019, diikuti oleh 10 lembaga PAUD dan pada Rabu 18 September 2019 diikuti oleh 10 lembaga PAUD dengan proses pelaksanaan strategi kemitraan sebagai berikut:

1. Sosialisasi program kegiatan pengabdian masyarakat kepada HIMPAUDI kecamatan Kedungbanteng kabupaten Banyumas.

Sosialisasi program kegiatan pengabdian masyarakat kepada HIMPAUDI kecamatan Kedungbanteng kabupaten Banyumas dilakukan oleh penulis pada rapat kerja pengurus HIMPAUDI yang dilaksanakan pada tanggal 24 Agustus 2019. Pada saat sosialisasi dilakukan diskusi antara penulis dengan pengurus HIMPAUDI mengenai kegiatan apa yang dibutuhkan oleh setiap lembaga PAUD berdasarkan permasalahan yang tengah dihadapi saat ini dalam penyelenggaraan layanan PAUD.

Berdasarkan hasil diskusi antara penulis dengan pengurus HIMPAUDI kecamatan Kedungbanteng kabupaten Banyumas dapat diketahui bahwa ada tiga permasalahan yang dihadapi dalam penyelenggaraan layanan PAUD. Pertama, orangtua kurang peduli dengan rekam jejak serta permasalahan terkait dengan tumbuh-kembang. Kedua, jalinan komunikasi antara orangtua dengan guru PAUD masih lemah. Orangtua menyerahkan tanggungjawab mendidik anak kepada para guru. Ketiga, orangtua belum memiliki kemampuan yang memadai dalam memberikan stimulasi edukasi pada anak untuk mengoptimalkan tumbuh-kembangnya.

Dari ketiga masalah di atas kemudian pengurus HIMPAUDI kecamatan Kedungbanteng kabupaten Banyumas meminta kepada penulis untuk melakukan kerjasama (kemitraan) dalam pelaksanaan layanan Bimbingan dan Konseling melalui kegiatan parenting. Penulis kemudian menyanggupi kemudian penulis dan pengurus HIMPAUDI kecamatan Kedungbanteng kabupaten Banyumas bermusyawarah menentukan tema kegiatan parenting.

Berdasarkan hasil musyawarah kemudian ditetapkan tema kegiatan parenting sebagai berikut: "Keselarasan Pola Asuh Keluarga dengan Lembaga Pendidikan”. Setelah tema disepakati kemudian dibuat kesepakatan mengenai waktu pelaksanaan kegiatan parenting, yaitu pada Selasa 17 September 2019 diikuti oleh 10 lembaga PAUD dan pada Rabu 18 September 2019 diikuti oleh 10 lembaga PAUD. 
2. Penandatanganan Memorandum of Understanding (MoU) antara Fakultas Tarbiyah dan Ilmu Keguruan (FTIK) IAIN Purwokerto dengan HIMPAUDI kecamatan Kedungbanteng tentang pelaksanaan layanan bimbingan dan konseling melalui kegiatan parenting bagi wali murid.

MoU antara Fakultas Tarbiyah dan Ilmu Keguruan (FTIK) IAIN Purwokerto dengan HIMPAUDI kecamatan Kedungbanteng kabupaten Banyumas dibuat oleh Dekan FTIK dan disepakati oleh Dekan FTIK dengan ketua HIMPAUDI beserta 21 saksi. 1 saksi adalah penulis dan 20 saksi adalah kepala PAUD di kecamatan Kedungbanteng kabupaten Banyumas.

Hal-hal yang tersaji dan disepakati dalam Mou antara dekan FTIK IAIN Purwokerto, ketua HIMPAUDI dan para saksi adalah sebagai berikut:

a. Pihak pertama dalam MoU adalah H. Suwito, M.Ag sebagai dekan FTIK.

b. Pihak kedua dalam MoU adalah Fitri Nurul Hidayati, SE sebagai ketua HIMPAUDI.

c. Pihak pertama dengan pihak kedua bersepakat melaksanakan kegiatan seminar parenting.

d. Kegiatan seminar parenting dilaksanakan di kecamatan Kedungbanteng kabupaten Banyumas pada tanggal 17 September 2019 dan 18 September 2019.

e. Pihak pertama berkewajiban mengirim satu dosen sebagai narasumber dalam seminar parenting.

f. Pihak kedua berkewajiban mengundang peserta kegiatan seminar parenting.

g. Pihak kedua berkewajiban menyediakan akomodasi untuk peserta kegiatan parenting.

h. Pihak kedua berkewajiban menyediakan akomodasi untuk narasumber yang dikirim oleh pihak pertama.

i. Pihak kedua berkewajiban menyiapkan sarana dan prasarana yang dibutuhkan untuk menyelenggarakan kegiatan seminar parenting.

Berikut adalah foto sebagai bukti dokumen MoU antara Dekan FTIK IAIN Purwokerto dengan ketua HIMPAUDI kecamatan Kedungbanteng kabupaten Banyumas: 

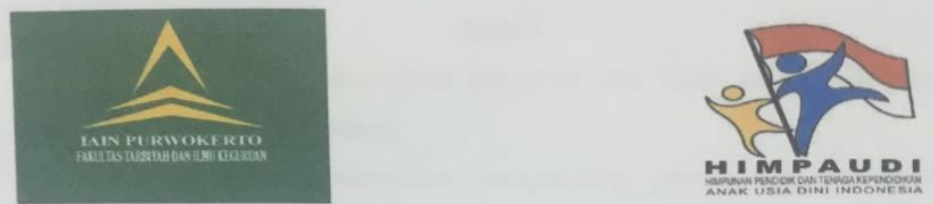

MEMORANDUM OF UNDERSTANDING

(MoU)

FAKULTAS TARBIYAH DAN ILMU KEGURUAN (FTIK) IAIN PURWOKERTO DENGAN

HIMPAUDI KECAMATAN KEDUNGBANTENG KABUPATEN BANYUMAS

Nomor: $888 / \ln .22 / 0$. FTKK/PP.00g/lX/20y

Nomor: $03 / A / P C \cdot H I M P . K D B T / W / 2019$

Hal : Penyelenggaraan Seminar Parenting

\section{Pasal 1}

(1) Perjanjian kerjasama ini disusun oleh pihak pertama dengan pihak kedua.

(2) Pihak pertama dalam perjanjian ini adalah Dr. H. Suwito, M.Ag selaku Dekan FTIK IAIN Purwokerto.

(3) Pihak kedua dalam perjanjian ini adalah Fitri Nurul Hidayati, SE selaku ketua HIMPAUDI kecamatan Kedungbanteng kabupaten Banyumas.

\section{Pasal 2}

(1) Pihak pertama dengan pihak kedua bersepakat melaksanakan kegiatan seminar parenting.

(2) Kegiatan seminar parenting dilaksanakan di kecamatan Kedungbanteng kabupaten Banyumas pada tanggal 17 September 2019 dan 18 September 2019. 


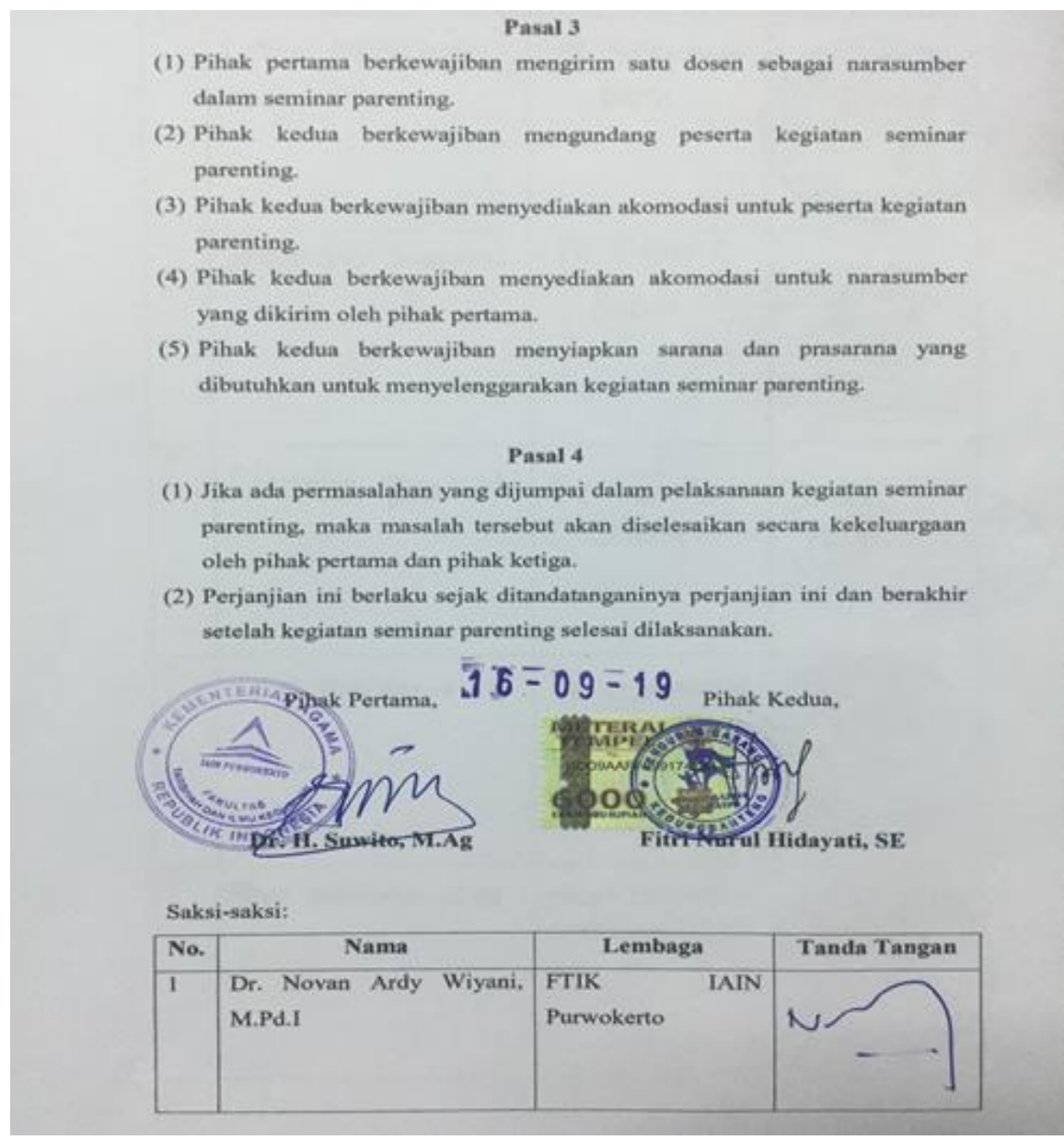

\section{Gambar 1. MoU Kegiatan Pengabdian kepada Masyarakat}

3. Pelaksanaan layanan bimbingan dan konseling melalui kegiatan parenting bagi wali murid.

Pelaksanaan layanan bimbingan dan konseling melalui kegiatan parenting bagi wali murid pada lembaga PAUD di kecamatan Kedungbanteng kabupaten Banyumas dilakukan melalui dua tahap berikut ini:

a. Tahap Pertama.

Tahap pertama dilaksanakan pada Selasa 17 September 2019 di UPK Kedungbanteng. Para wali murid yang hadir sebagai peserta kegiatan berasal dari 10 lembaga PAUD berikut ini:

1) KB Satria Jaya Melung.

2) KB Putra Mandiri Keniten.

3) KB Banyu Belik Karangnangka.

4) KB al-Manar Beji.

5) PosPAUD Mawar VII Dawuhan Kulon.

6) KB Asy-Syahadah Karangnangka.

7) KB Islam al-Izzah Karangsalam. 
8) KB Patriadira Kalikesur.

9) KB Nur Amanah Kutaliman.

10) KB Az-Zahra Dawuhan Kulon.

Jumlah peserta yang hadir pada tahap pertama sebanyak 159 peserta. Sesuai dengan tema yang telah disepakati maka materi yang diberikan dalam kegiatan parenting antara lain:

1) Kewajiban mendidik anak dalam perspektif Islam.

2) Peran orangtua dalam mendidik anak.

3) Kerjasama antara orangtua dengan guru PAUD dalam mendidik anak.

4) Prinsip-prinsip kerjasama antara orangtua dengan guru PAUD dalam mendidik anak.

Materi parenting di atas disampaikan melalui model seminar. Setelah menyampaikan materi kemudian dilakukan sesi tanya-jawab. Pada sesi tanya jawab ini para peserta (wali murid) dapat menyampaikan keluhan-keluhannya dalam mendidik anak. Kemudian penulis sebagai narasumber menjawab pertanyaan-pertanyaan tersebut.

Tentunya pada sesi seminar tidak semua wali murid memiliki kesempatan untuk bertanya. Kemudian tentu saja tidak semua wali murid memiliki keberanian untuk menyampaikan keluhan-keluhannya dalam mendidik anak. Berdasarkan kedua hal tersebut kemudian setelah sesi seminar parenting penulis difasilitasi oleh pengurus HIMPAUDI sebuah tempat untuk menyelenggarakan layanan konsultasi bagi wali murid secara individu.

Keluhan-keluhan atau masalah-masalah yang disampaikan oleh orangtua dalam mendidik anak antara lain:

1) Anak manja, maunya ditunggui saat belajar di lembaga PAUD.

2) Anak kecanduan gadget.

3) Anak tidak mau berangkat ke sekolah karena takut ditunjuk oleh guru.

4) Anak malas mengaji.

5) Anak boros, sukanya jajan dan membeli jajanan yang kurang sekat.

b. Tahap Kedua.

Tahap kedua dilaksanakan pada Rabu 18 September 2019 bertempat di UPK Kedungbanteng. Wali murid yang hadir dalam kegiatan parenting sebanyak 101 peserta yang berasal dari lembaga PAUD berikut ini:

1) KB Aisyiyah Beji.

2) PosPAUD Mawar II Baseh.

3) PosPAUD Windu Cahaya Windujaya.

4) PosPAUD Cempaka III Dawuhan Wetan.

5) PAUD TPQ An-Nasriyah Beji. 
6) KB Tunas Perjuangan Kalisalak.

7) KB Tunas Bangsa Kedungbanteng.

8) KB Bunga Pertiwi Baseh.

9) KB Berseri Kebocoran.

10) KB Tunas Harapan Windujaya.

Berdasarkan hasil pelaksanaan pada tahap pertama, maka pada tahap kedua ada skenario yang berbeda dari pelaksanaan seminar parenting. Skenario seminarnya adalah sebagai berikut:

1) Penulis sebagai narasumber menampilkan video terkait dengan problem tumbuhkembang anak di hadapan wali murid.

2) Berdasarkan video yang diputar kemudian penulis memberikan kesempatan kepada wali murid untuk memberikan tanggapan terkait dengan isi video kemudian penulis mengomentari tanggapan tersebut.

3) Berdasarkan hasil tanggapan dan komentar kemudian penulis memberikan kesempatan kepada wali murid untuk bertanya. Setelah wali murid bertanya kemudian penulis menjawab pertanyaan dari wali murid.

4) Setelah sesi tanya-jawab selesai kemudian dilanjutkan dengan sesi penyampaian materi kegiatan parenting dengan perubahan materi sebagai berikut:

a) Posisi anak dalam perspektif Islam.

b) Peran orangtua dalam mendidik anak berdasarkan posisi anak.

c) Kerjasama antara guru dan orangtua dalam mendidik anak.

d) Strategi mendiagnosa masalah perkembangan pada anak.

e) Prinsip-prinsip dalam pengambilan keputusan oleh orangtua dalam menyelesaikan masalah anak berdasarkan hasil diagnosa.

5) Setelah penyampaian materi selesai dilakukan kemudian dilanjutkan dengan sesi tanyajawab, tetapi karena keterbatasan waktu sesi tanya jawab dilakukan hanya 1 sesi.

6) Setelah sesi tanya jawab selesai kemudian kegiatan parenting ditutup. Pasca penutupan penulis dibantu oleh pengurus HIMPAUDI mengadakan layanan konseling individu di tempat yang telah disediakan oleh pengurus HIMPAUDI. 


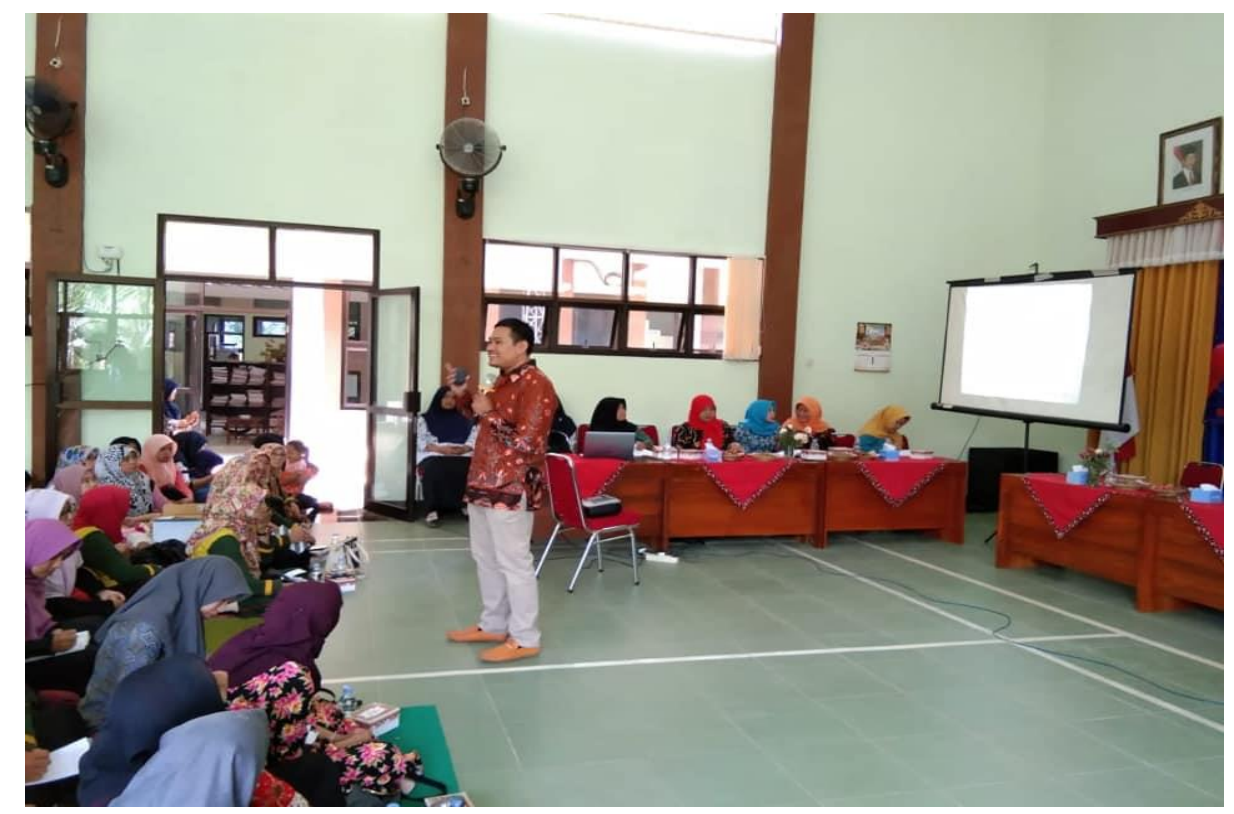

Gambar 2. Penulis menyampaikan materi kegiatan parenting

4. Pelaporan kegiatan pelaksanaan layanan bimbingan dan konseling melalui kegiatan parenting bagi wali murid.

Pelaporan kegiatan pelaksanaan layanan bimbingan dan konseling melalui kegiatan parenting bagi wali murid di lembaga PAUD kecamatan Kedungbanteng kabupaten Banyumas dilakukan oleh penulis dan pengurus HIMPAUDI. Pengurus HIMPAUDI menyusun laporan kegiatan parenting dan menyampaikan laporannya kepada 20 orang kepala PAUD di kecamatan Kedungbanteng kabupaten Banyumas. Hal-hal yang dilaporkan antara lain:

a. Pelaporan jumlah peserta atau wali murid yang hadir.

b. Pelaporan penggunaan anggaran kegiatan parenting.

c. Pelaporan penggunaan sarana dan prasarana.

Sedangkan pelaporan kegiatan parenting yang dilakukan oleh penulis disusun dengan membuat artikel hasil pengabdian kepada masyarakat. Artikel yang dibuat kemudian dilaporkan kepada Kaprodi PIAUD FTIK IAIN Purwokerto. Setelah artikel diterima oleh Kaprodi kemudian penulis melakukan submite artikel pada jurnal pengabdian kepada masyarakat.

Bersasarkan pelaksanaan keempat tahap di atas dapat diperoleh deskripsi mengenai faktor pendukung dan faktor penghambat dalam praktek strategi kemitraan pelaksanaan layanan bimbingan dan konseling melalui kegiatan parenting bagi wali murid pada lembaga PAUD di kecamatan Kedungbanteng kabupaten Banyumas. 


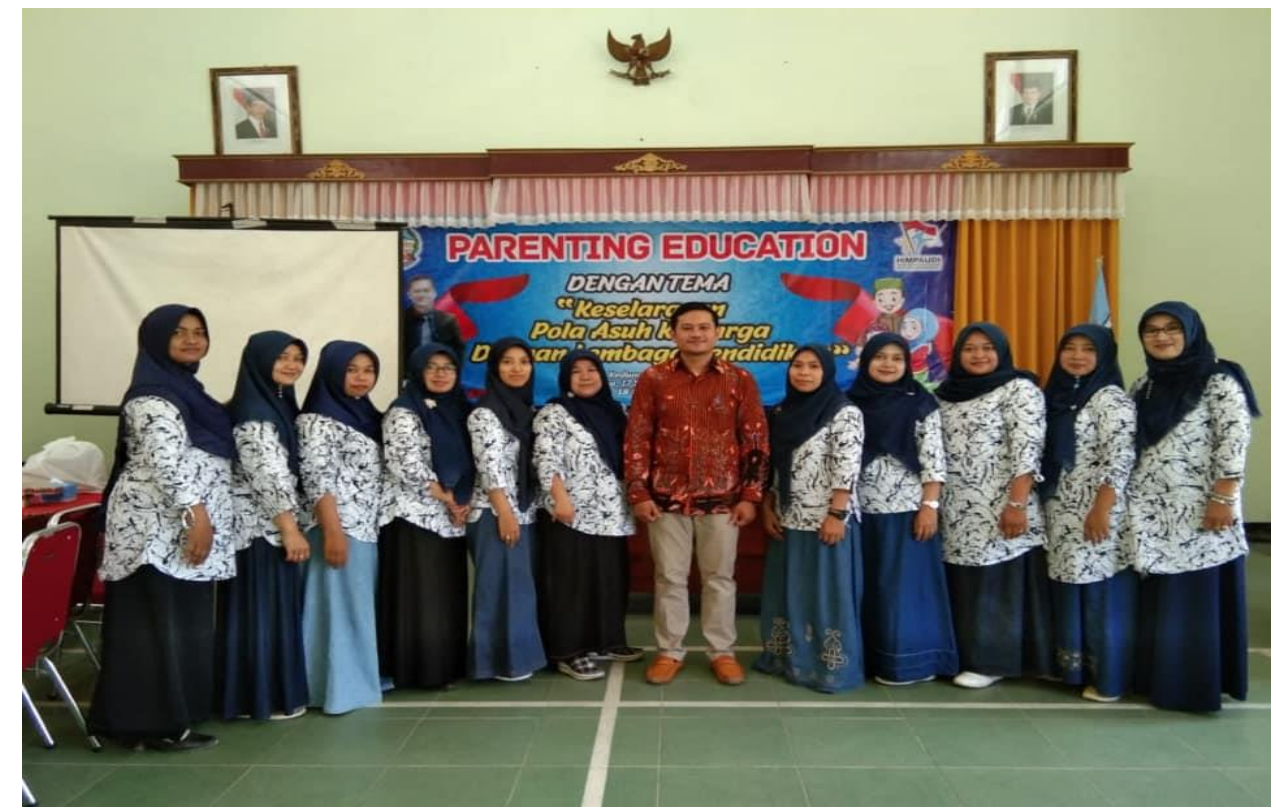

Gambar 3. Penulis bersama dengan pengurus HIMPAUDI kecamatan Kedungbanteng kabupaten Banyumas

Terdapat empat faktor pendukung. Pertama, ketersediaan sarana dan prasarana untuk melaksanakan kegiatan parenting dan kegiatan layanan konsultasi. Pengurus HIMPAUDI dipinjami dua prasarana, yaitu auditorium untuk pelaksanaan kegiatan parenting dan satu lokal ruang kerja untuk melaksanakan kegiatan layanan konsultasi oleh UPK Kedungbanteng. Sedangkan sarana pendukung yang dipinjamkan kepada HIMPAUDI antara lain meja dan kursi, papan tulis, serta LCD proyektor. Kedua, Korwilcam UPK Kedungbanteng beserta pemilik PAUD ikut hadir dan mengikuti kegiatan parenting. Kedatangan kedua pejabat kedinasan tersebut memacu kepala PAUD untuk mengirimkan wali murid sebagai peserta kegiatan parenting sebanyak mungkin. Ketiga, pengurus HIMPAUDI sebagian besar adalah pengurus yang baru sehingga mereka memiliki semangat yang masih sangat tinggi untuk melaksanakan program kerja pengurus HIMPAUDI. Keempat, ketersediaan anggaran yang memadai dari HIMPAUDI untuk menyelenggarakan kegiatan parenting, di mana angaran tersebut bersumber dari iuran setiap lembaga PAUD di kecamatan Kedungbanteng kabupaten Banyumas.

Kemudian ada dua faktor penghambat dalam pelaksanaan kegiatan parenting dan kegiatan layanan konsultasi. Pertama, pengurus HIMPAUDI tidak menggandakan dan memberikan lembar presentasi materi kegiatan parenting pada peserta. Kedua, kegiatan parenting tidak dilaksanakan secara tepat waktu dikarenakan keterlambatan kedatangan wali murid di lokasi kegiatan.

Sementara itu ada tiga hal yang dihasilkan dari pelaksanaan kegiatan parenting dan kegiatan layanan konsultasi. Pertama, wali murid memiliki tambahan pengetahuan terkait dengan metode pendidikan anak untuk mengoptimalkan tumbuh-kembang anak. Kedua, wali murid yang memiliki 
permasalahan terkait dengan tumbuh-kembang anaknya mendapatkan deskripsi solusi penanganan masalahnya. Ketiga, setiap lembaga PAUD memiliki salinan MoU kerjasama (kemitraan) antara FTIK IAIN Purwokerto dengan HIMPAUDI kecamatan Kedungbanteng kabupaten Banyumas yang dapat digunakan sebagai salah satu dokumen pendukung dalam kegiatan akreditasi PAUD.

\section{KESIMPULAN DAN SARAN}

Strategi kemitraan pelaksanaan layanan bimbingan dan konseling melalui kegiatan parenting bagi wali murid pada lembaga PAUD di kecamatan Kedungbanteng kabupaten Banyumas dilaksanakan melalui empat tahap, yaitu sosialisasi program pengabdian kepada masyarakat, penandatanganan MoU antara Dekan FTIK IAIN Purwokerto dengan ketua HIMPAUDI, pelaksanaan kegiatan parenting, dan pelaporan hasil kegiatan parenting.

Bentuk layanan bimbingan dan konseling yang diberikan kepada wali murid adalah layanan konsultasi, di mana layanan konsultasi ini dilakukan secara individu pada ruangan yang telah disediakan oleh pengurus HIMPAUDI. Pada layanan konsultasi tersebut wali murid sebagai klien dan penulis sebagai konselor membicarakan berbagai problem yang dihadapi oleh klien dalam mengotimalkan tumbuh-kembang anak di lingkungan keluarga.

\section{UCAPAN TERIMA KASIH}

Ucapan terima kasih penulis sampaikan kepada:

1. Dekan Fakultas Tarbiyah dan Ilmu Keguruan (FTIK) IAIN Purwokerto

2. UPK Kedungbenteng Kabupaten Banyumas

3. Pengurus HIMPAUDI Kecamatan Kedungbenteng Kabupaten Banyumas

4. Seluruh Lembaga PAUD dan Wali murid PAUD Kecamatan Kedungbenteng Kabupaten Banyumas yang telah terlibat pada Kegiatan Parenting

\section{DAFTAR PUSTAKA}

Izzaty, R. E. (2017). Model Konseling Anak Usia Dini. Bandung: Rosda Karya.

Latif, M. (2014). Orientasi Baru Pendidikan Anak Usia Dini. Jakarta: Kencana Prenada Media Group.

Putro, K. Z., \& Suyadi. (2016). Bimbingan dan Konseling PAUD. Bandung: Rosda Karya.

Saripudin, A. (2019). Kompetensi Guru Pendamping PAUD dalam Memenuhi Standar Layanan PAUD Non Formal di Kabupaten Tasikmalaya. Jurnal Pendidikan Anak: Awlady, 5(2).

Wiyani, N. A. (2014). Psikologi Perkembangan Anak Usia Dini. Yogyakarta: Gavamedia. 
Wiyani, N. A. (2016). Konsep Dasar PAUD. Yogyakarta: Gavamedia.

Yani, A., Khaeriyah, E., \& Ulfah, M. (2017). Implementasi Islamic Parenting dalam Membentuk Karakter Anak Usia Dini di RA at-Taqwa Kota Cirebon. Jurnal Pendidikan Anak: Awlady, $3(1), 153-174$. 